\title{
Inuit health system must move past suicide prevention to "unlock a better reality," conference told
}

I nuit communities have been dysfunctional for the past 30-50 years, with suicide now touching "each and every one of us," but this must not be accepted as normal, attendees at the National Aboriginal Health Association conference in Ottawa, Ontario, were told Nov. 24.

"We all have brothers, sisters and friends who have died by suicide," Natan Obed, director of social and cultural development for Nunavut Tunngavik Inc., which represents beneficiaries of the Nunavut Land Claim Agreement, told the opening session at the three-day conference. "But I contend that our people [in the past] had a low death by suicide rate. It is not our fate in life to be at risk."

To "unlock a better reality" the definition of "normal" must be changed, he said, adding that programs to promote wellness and community development should not be presented as "suicide prevention" programs.

"I don't want my sons thinking that when they go on an on-the-land program, they are being saved from suicide. ... We have to be careful not to champion these [programs] in the name of suicide."

Obed, who lives in Iqaluit, said Nunavut's system of health care, in which citizens go to nursing stations but must travel south for any substantial medical care, is similar to patterns set during the tuberculosis epidemic in the 1950s when "ships came and took our people south." Many families still do not know what happened to the children who boarded the ships, he added.

Obed also said that stronger links have to be made between the health status of Inuit people and the historical trauma and physical and sexual abuse they have suffered. "We have not come to terms with the fact that our kids are growing up in a dysfunctional state and

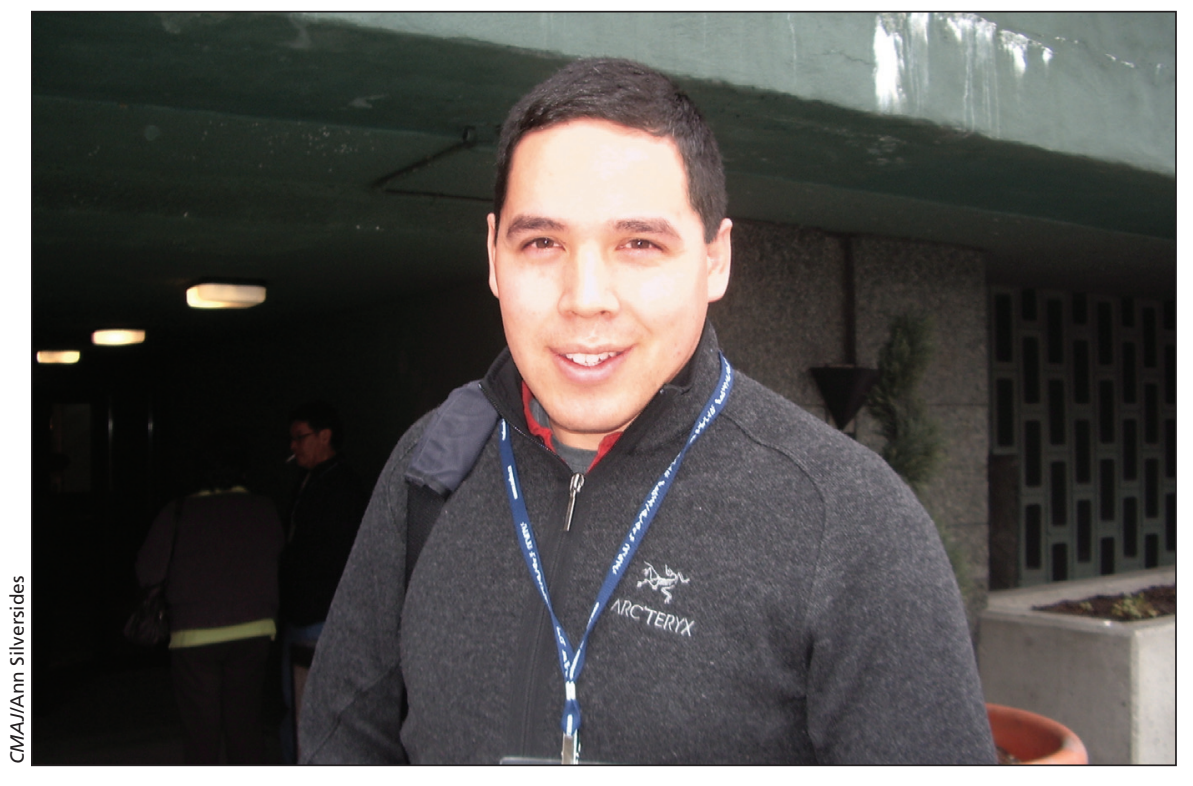

Natan Obed, director of social and cultural development for Nunavut Tunngavik Incorporated, says the definition of "normal" must be changed.

are burdened with experiences" that will affect their ability to live "full and rich" lives.

"This is difficult to talk about," he told the more than 700 delegates. "It is almost like dirty secrets in a family, but we really have to discuss this."

Suicide rates among Inuit youth are 11 times the national average, according to Health Canada, while overall rates among Inuit are about six times the national average.

In August, the National Aboriginal Health Organization surveyed Inuit, Métis and First Nations people about their priorities for health, chief executive officer Paulette Tremblay told the conference.

Inuit identified as top priorities, in order of importance: mental health, cancer and substance abuse, while priorities cited by Métis were diabetes, substance abuse, diet and nutrition, and cancer, she said. First Nations identified as top priorities diabetes, substance abuse, mental health and diet and nutrition. There are a combined 1.2 million
First Nations, Inuit and Métis people in Canada.

Meanwhile, James Makokis, a medical student at the University of Ottawa, told the conference that like many other young people - who make up 50\% of the Aboriginal population in Canada - he has returned to traditions such as acknowledging his spirit names.

"A lot of this was lost through long periods of trauma in Canadian history ... [but] our spirit names ground us and provide our relationship to people in our community," said Makokis, who is from the Saddle Lake Cree Nation in Alberta.

Indeed, the important social determinants of health for the aboriginal community are culture, spirituality and ceremony, he said. "We can go to university to learn, but how we help people lies in the foundation of ceremony, language and culture." - Ann Silversides, CMAJ

DOI:10.1503/cmaj.109-3117 